\title{
Sistem Tempat Parkir Terintegrasi yang Dilengkapi dengan Aplikasi Mobile dan Mikrokontroller
}

\author{
Kenji Andrean, Departemen Informatika, Institut Sains dan Teknologi Terpadu Surabaya, \\ Hendrawan Armanto, Departemen Informatika, Institut Sains dan Teknologi Terpadu Surabaya, dan \\ C. Pickerling, Departemen Informatika, Institut Sains dan Teknologi Terpadu Surabaya
}

\begin{abstract}
Abstrak - Saat ini tempat parkir di Indonesia khususnya kota Surabaya masih menggunakan tiket print out sebagai penanda seseorang dapat parkir disana. Hal ini dirasa lambar dan kurang efisien, sehingga dapat menimbulkan kendala berupa penumpukan atau antrian mobil yang hendak keluar dikarenakan masing-masing mobil membutuhkan waktu minimal 2-3 menit untuk menyerahkan tiket, membayar, menerima kembalian, dan menunggu gerbang parkir terbuka. Melihat permasalahan yang ada, maka pada penelitian ini, peneliti berusaha mengembangkan sistem yang dapat mengurangi waktu yang dibutuhkan setiap mobil menjadi maksimal 1 menit sehingga dapat mengurangi penumpukan atau antrian mobil yang terjadi. Penelitian ini menerapkan metode experimental dimana sistem yang terbentuk akan diujicobakan langsung ke masyarakat untuk melihat hasilnya secara nyata dan mengetahui apakah tujuan penelitian ini telah tercapai. Sistem yang dibentuk dalam penelitian ini melibatkan aplikasi mobile yang digunakan oleh user, website yang digunakan oleh admin dan mikrokontroler yang digunakan untuk palang parkir. Pada akhirnya, evaluasi penelitian ini dilakukan menggunakan acceptance test oleh masyarakat (dibuktikan dengan kuisioner), dimana hasil akhirnya menunjukan bahwa $100 \%$ tester menyatakan penelitian ini memudahkan pengguna dalam melakukan pemesanan dan pembayaran parkir.
\end{abstract}

Kata Kunci - Android, Flutter, Gerbang, Tempat Parkir

\section{Pendahuluan}

$\mathrm{P}$ erkembangan teknologi informasi dan komunikasi memang tidak akan pernah berhenti. Banyak teknologi yang semakin berkembang, salah satunya adalah teknologi Mobile Application (Android/iOS). Teknologi ini memudahkan orang untuk saling berkomunikasi dan bertukar informasi melalui mobile device seperti smartphone. Sekarang penyediaan jasa melalui smartphone sedang berkembang pesat. Penyediaan jasa pada smartphone ini berfungsi agar kita tidak perlu repot, dan membuat proses semakin singkat hanya dengan melalui smartphone.

Kenji Andrean, Teknik Informatika Institut Sains dan Teknologi Terpadu Surabaya, Surabaya, Jawa Timur, Indonesia (e-mail: kenji1@mhs.stts.edu).

Hendrawan Armanto, Teknik Informatika, Institut Sains dan Teknologi Terpadu Surabaya, Surabaya, Jawa Timur, Indonesia (e-mail: hendrawan@stts.edu)

C. Pickerling, Teknik Informatika, Institut Sains dan Teknologi Terpadu Surabaya, Surabaya, Jawa Timur, Indonesia (e-mail: pickerling@stts.edu)
Selama ini tempat parkir selalu menggunakan mesin parkir saat masuk dan operator saat keluar. Tiket juga akan dicetak untuk user dan user harus menyimpan tiket tersebut sampai keluar. Hal ini dirasa kurang efektif, dikarenakan kurangnya proses otomisasi pada saat keluar dan juga ada kemungkinan akan kehilangan karcis parkir.

Melihat dari permasalahan yang ada, maka munculah ide untuk membuat aplikasi pembayaran untuk tempat parkir. Dengan adanya aplikasi ini diharapkan dapat membantu mempermudah proses parkir dari masuk hingga keluar parkiran. User tidak perlu menyimpan tiket karena tiket sudah terdapat dalam aplikasi. Tujuan pembuatan aplikasi dapat dilihat dari poin-poin berikut ini:

- Mempermudah user dalam melakukan proses pembayaran tempat parkir.

- Mempersingkat proses masuk sampai keluar tempat parkir. - Mempermudah user untuk mendapatkan tempat parkir.

\section{TINJAUAN PUSTAKA}

Berdasarkan sistem yang dibuat untuk memudahkan proses parkir. Penjelasan yang diberikan pada tinjauan pustaka dapat membantu lebih memahami sistem ini secara garis besar. Komponen-komponen yang dijelaskan antara lain Flutter Framework, Raspberry Pi, Laravel Framework, Firebase, Xendit untuk membantu pembuatan aplikasi ini. Berikut ini merupakan penjelasan terhadap tiap-tiap komponen tersebut.

\section{A. Flutter Framework}

Flutter [1] akan digunakan sebagai framework untuk membuat aplikasi mobile pada sistem yang akan dibuat. Berikut adalah penjelasan flutter. Flutter adalah Mobile App SDK milik Google dimana developer dapat membuat aplikasi untuk IOS dan Android dengan menggunakan Bahasa dan source code yang sama [2]. Bahasa yang digunakan pada flutter adalah Bahasa pemrograman Dart. Pada flutter, developer dapat membuat aplikasi secara native dengan menggunakan Bahasa pemrograman Dart. Flutter juga mempunyai widget nya sendiri. Dengan didukung oleh Google, flutter dapat berkembang sangat cepat dan dapat bersaing dengan Xamarin, React Native, dan framework mobile lainnya. Berikut adalah gambar dari struktur dari flutter framework. 


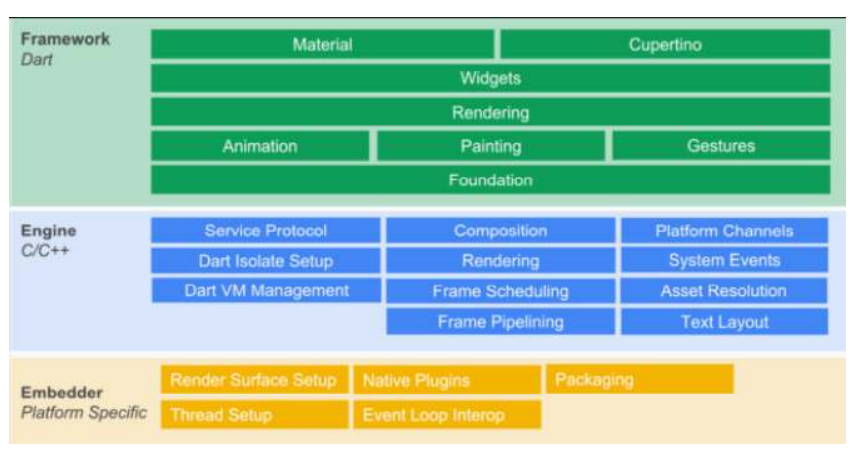

Gambar. 1. Struktur Flutter

Setelah melihat gambar 1, struktur dari flutter maka perlu diketahui apa kelebihan dan kekurangan dari flutter framework dibandingkan framework lainnya. Kelebihan flutter akan dijelaskan dalam poin-poin, berikut:

- Produktivitas Tinggi

Karena flutter adalah cross-platform, dengan 1 codebase dapat diciptakan aplikasi IOS dan Android. Dengan ini tentunya akan menghemat waktu dan tenaga.

- Performa Hebat

Dart mengkompilasi kedalam kode native dan tidak perlu lagi mengakses OEM widget dikarenakan flutter mempunyai widget nya sendiri. Demikian flutter dapat berjalan dengan cepat dan mengurangi masalah performa.

- Development yang Ringkas dan Cepat

Salah satu fitur flutter yang paling dipuji adalah hot reload. Dimana hot reload ini berguna untuk menampilkan perubahan yang dilakukan pada kode secara instan pada emulator, simulator, dan hardware. Dengan kurang dari beberapa detik, kode yang dirubah dimuat ulang dengan aplikasi masih berjalan tanpa perlu dilakukan restart. Hal ini sangat bagus bukan hanya untuk membuat UI atau menambahkan fitur tetapi juga untuk bug fixing.

- Open Source

Flutter dan Dart, keduanya open source dan gratis untuk digunakan. Keduanya juga memberikan dokumentasi yang bagus dan lengkap serta ada komunitas yang membantu untuk menyelasaikan masalah yang ditemukan saat proses development.

Selain kelebihan pasti juga terdapat kekurangan, flutter memiliki kekurangan dikarenakan framework ini merupakan framework baru. Kekurangan flutter antara lain:

\section{- Komunitas}

Dikarenakan flutter masih baru, masih sedikit tutorial yang dapat ditemukan secara online. Meskipun komunitas flutter terus berkembang, ada beberapa jawaban yang tidak dapat ditemukan pada komunitas.

- Third Party Libraries

Karena masih baru, third party libraries pada flutter sedikit, akan tetapi seiring berjalannya waktu banyak third party yang membuat library nya dapat digunakan oleh flutter. Walaupun tidak sebanyak pesaing flutter yaitu react native dimana banyak third party libraries yang sudah tersedia.

\section{B. Raspberry Pi}

Raspberry pi [3] adalah komputer berukuran seperti credit card dan murah yang dapat ditampilkan pada monitor komputer atau TV, dan menggunakan mouse dan keyboard standard. Raspberry pi merupakan device kecil yang dapat membuat semua orang pada berbagai umur dapat menjelajah apa itu komputasi, dan mempelajari bagaimana cara membuat program dengan scratch dan python. Raspberry pi dapat melakukan semua hal yang dapat diharapkan dari sebuah komputer, mulai dari menjelajah internet dan memainkan video HD, membuat spreadsheets, wordprocessing, dan memainkan game.

Raspberry pi dibuat oleh Raspberry Pi Foundation, foundation ini berbadan amal dan berbasis di UK (United Kingdom) dimana mereka memiliki tujuan agar seluruh orang didunia dapat menggegam kekuatan komputasi dan pembuatan digital. Keinginan mereka adalah agar orangorang dapat mempelajari komputasi, menghidupkan ide kreatif, dan juga menyelesaikan masalah. Raspberry pi foundation menyediakan raspberry pi untuk tujuan tersebut.

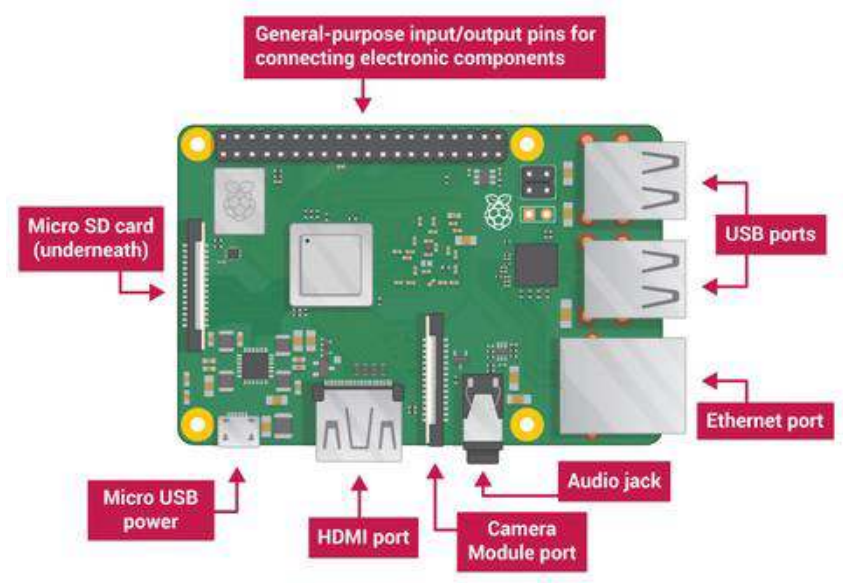

Gambar. 2. Port Raspberry Pi 3 Model B+

Pada gambar 2 dapat dilihat port-port yang disediakan oleh raspberry. Raspberry pada gambar adalah raspberry yang akan digunakan untuk keperluan penelitian ini. Berikut adalah penjelasan masing-masing port:

- Universal Serial Bus (USB)

USB port digunakan untuk menyambungkan berbagai jenis komponen, komponen yang biasanya dipakai adalah mouse dan keyboard.

- High Definition Media Interface (HDMI)

Port HDMI menyalurkan video dan audio pada monitor yang tersambung.

- Audio Jack

Audio jack dapat membuat user menyambungkan headphone atau speaker.

- Micro USB

Port mikro usb digunakan untuk memberikan daya saja, jangan menyambungkan hal lainnya ke port ini. Selalu sambungkan power setelah selesai menyambungkan hal lainnya. 
- General Purpose Input Output (GPIO)

Port GPIO memungkinkan user untuk mengkontrol dan menerima input dari komponen elektrik apapun.

\section{- SD Card}

Raspberry PI menggunakan SD card sama dengan komputer menggunakan hard drive. SD card menyediakan memori internal dan tempat penyimpanan.

- Ethernet Port

Port ethernet digunakan untuk menyambungkan internet melalui kabel LAN. Pada raspberry pi 3 model B+ sudah tersedia Wi-Fi jadi dapat juga menggunakan wi-fi untuk melakukan sambungan ke internet.

- Camera Module Port

Port ini digunakan untuk menyambungkan modul kamera. Raspberry pi menyediakan kamera resmi yang dibuat. Port ini digunakan untuk menyambungkan kamera tersebut.

Setelah mengetahui fungsi dari setiap port pada raspberry akan dijelaskan juga komponen-komponen yang dipakai untuk mendukung jalannya sistem. Terdapat 3 komponen penting dalam raspberry. Berikut adalah penjelasan dari komponen-komponen tersebut:

\section{- Servo}

Servo akan digunakan sebagai alat pemutar gerbang. Dimana servo akan diberikan perintah oleh raspberry dan akan melakukan putaran sesuai perintah yang sudah di program. Servo akan mengangkat gerbang sebanyak 90 derajat dan akan menutup gerbang kembali sebanyak 90 derajat lagi.

- Ultrasonic

Ultrasonic akan digunakan sebagai alat untuk mengecek apakah masih ada mobil dibawah gerbang parkir. ultrasonic pada umumnya berguna untuk mendapatkan jarak antara ultrasonic dengan benda didepannya. Pada penelitian ini, ultrasonic akan mengecek apakah ada kendaraan didepannya atau tidak. jika ada maka ultrasonic akan memberi tahu raspberry untuk menahan servo agar tidak ditutup. Jika tidak ada mobil maka raspberry akan menutup servo.

\section{- Pi Camera}

Pi camera adalah komponen milik raspberry pi dimana digunakan untuk mengambil gambar ataupun video. Camera ini mudah untuk dipakai karena merupakan bagian dari raspberry pi. Kamera akan digunakan untuk mengambil gambar. Pada penelitian ini, kamera akan melakukan pengambilan gambar terhadap mobil yang berada pada gerbang masuk. Gambar akan disimpan pada database, gambar ini nantinya akan dipakai pada sistem untuk fitur report.

\section{Laravel Framework}

Laravel adalah framework bahasa pemrograman Hypertext Preprocessor (PHP) yang ditujukan untuk pengembangan aplikasi berbasis web dengan menerapkan konsep Model View Controller (MVC). Framework ini dibuat oleh Taylor Otwell dan pertama kali dirilis pada tanggal 9 Juni 2011. Laravel berlisensi open source yang artinya bebas digunakan tanpa harus melakukan pembayaran. Alamat website resmi dari framework Laravel adalah https://laravel.com
Framework Laravel versi 5.8 resmi dirilis pada tanggal 26 February 2019. Untuk menggunakan Laravel versi 5.8 komputer atau server yang digunakan harus memenuhi persyaratan sebagai berikut:

- $\mathrm{PHP}>=7.1 .3$

- BCMath PHP Extension

- Ctype PHP Extension

- JSON PHP Extension

- Mbstring PHP Extension

- OpenSSL PHP Extension

- PDO PHP Extension

- Tokenizer PHP Extension

- XML PHP Extension

Laravel menggunakan metode MVC, dimana M merupakan model, V merupakan View, dan C merupakan controller. Model mewakili struktur data. Biasanya model berisi fungsi-fungsi yang membantu seseorang dalam pengelolaan basis data seperti memasukkan data ke basis data, pembaruan data dan lain-lain. View adalah bagian yang mengatur tampilan ke pengguna. Bisa dikatakan berupa halaman web. Terakhir, Controller merupakan bagian yang menjembatani model dan view.

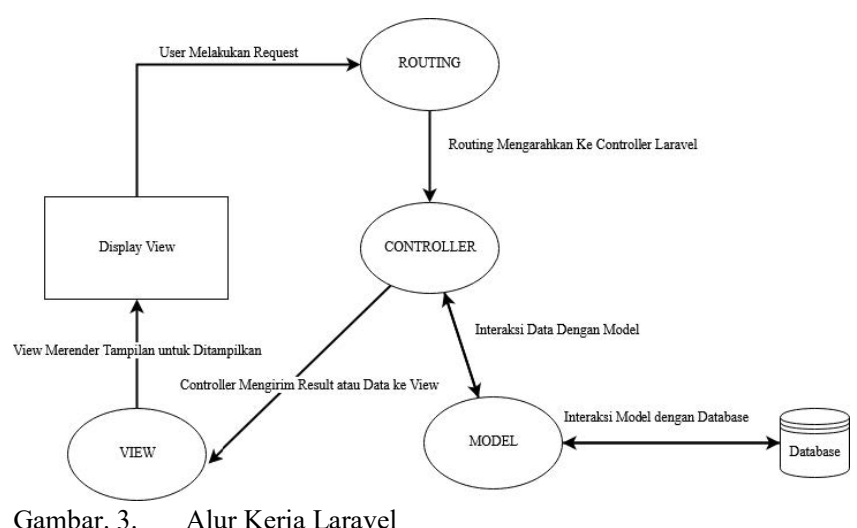

Gambar. 3. Alur Kerja Laravel

Pada gambar 3 merupakan alur kerja Laravel, pertama saat mengakses halaman selalu akan dimulai dari routing. Pada routing akan diolah halaman mana yang dituju dan memakai controller yang mana. Setelah melewati routing maka akan diproses melalui controller apa yang harus diberikan kepada view untuk ditampilkan. Controller akan mengambil data dari model dimana model akan melakukan pengambilan data melalui database. Setelah mendapat model atau proses controller selesai maka akan diberikan kedalam view. View akan melakukan render untuk menampilkan halaman yang ingin dilihat oleh user.

\section{Firebase}

Firebase [4] adalah layanan yang disediakan oleh Google untuk developer, dan memudahkan developer untuk mengembangkan aplikasi atau platform yang disediakan Google untuk membuat aplikasi mobile yang membantu developer untuk membuat, menumbuhkan, dan mengembangkan aplikasi. Ada beberapa layanan yang disediakan oleh firebase. Layanan tersebut terdiri dari 3 kategori besar yaitu, layanan untuk membuat aplikasi, 
layanan untuk menumbuhkan aplikasi, dan layanan untuk mengembangkan aplikasi. Beberapa layanan tersebut, antara lain:

- Firebase Authentication

Firebase authentication ini menangani user login, register dan mengidentifikasinya. Hal spesial dari authentication ini adalah dapat melakukan secure login dengan mudah, dimana hal tersebut susah untuk diimplementasikan sendiri. Dengan menggunakan authentication ini, aplikasi dapat menggunakan login milik facebook, google, twitter, github, dan masih banyak pilihan lainnya.

- Firebase Realtime Database

Firebase Realtime Database merupakan database yang disediakan oleh firebase dengan struktur NoSQL. Database ini dinilai dapat melakukan proses dan memberikan data kepada user secara realtime.

- Cloud Firestore

Cloud Firestore bukan merupakan layanan yang disediakan langsung oleh firebase tetapi merupakan layanan milik google cloud platform dimana disediakan SDK untuk dapat menggunakan firestore melalui firebase.

- Cloud Storage

Cloud storage menyediakan tempat penyimpanan file berskala besar. Cloud storage juga merupakan salah satu produk dari google cloud. Dengan adanya cloud storage for firebase, developer mempunyai SDK untuk digunakan pada aplikasi. SDK digunakan untuk mengupload dan mendownload file langsung dari cloud storage. Penyimpanan pada cloud storage juga disebut sebagai "bucket".

- Cloud Functions

Cloud function juga merupakan produk dari google cloud. Dengan disediakannya SDK untuk cloud function, developer dapat menuliskan dan menluncurkan kode yang dituliskan pada infrastruktur serverless milik google.

- Firebase Hosting

Firebase hosting adalah penyedia layanan hosting yang aman dan global. Firebase hosting ini sangat baik untuk mengantarkan static content seperti HTML, CSS, Images, JS.

- Firebase ML Kit

ML kit memberikan keuntungan berupa kekayaan machine learning yang dimilik oleh google, tanpa harus mempunyai pengetahuan tentang machine learning.

Tidak semua layanan diatas digunakan untuk membantu proses pembuatan sistem pada penelitian ini. Layanan yang dipakai adalah firebase authentication, firebase realtime database, cloud storage, dan cloud functions. Pertama authentication digunakan untuk mendaftarkan akun ke dalam authentication milik firebase sehingga pengecekan authentication dilakukan pada firebase. Kedua adalah realtime database, data disimpan pada database milik firebase, dimana semua proses data akan melalui firebase. Ketiga adalah cloud storage dimana cloud storage digunakan sebagai tempat penyimpanan gambar yang dikirimkan pada sistem. Dan terakhir cloud functions, terdapat beberapa pemrograman back-end pada cloud function seperti pembuatan data pada database saat user melakukan registrasi yang didaftarkan pada authentication. Pendaftaran pada authentication ini mentrigger function yang ada yaitu membuat data pada database.

\section{E. Xendit (Payment Gateway)}

Xendit adalah perusahaan penyedia layanan pembayaran di Indonesia yang membuat semua jenis transaksi menjadi mudah. Xendit memungkinkan user pemakai untuk dapat menerima dan mengirim dana dengan proses integrasi yang sederhana. Setiap dan semua transaksi dapat dengan mudah ditemukan dan dicatat dengan sistem deteksi penerimaan atau pengeluaran dana yang otomatis dan pemberitahuan yang instan [5]. Xendit menyediakan beberapa layanan seperti XenPayment, XenInvoice, XenDisburse, BatchDisburse. Pada penelitian ini digunakan XenInvoice sebagai sarana top up atau pengisian dana pada aplikasi.

Xendit sudah menyediakan user interface untuk penggunaan invoice, sehingga user hanya perlu memasukan callback API pada setting di xendit. Callback API ini akan dipanggil saat user yang melakukan top up sudah menyelesaikan pembayarannya.

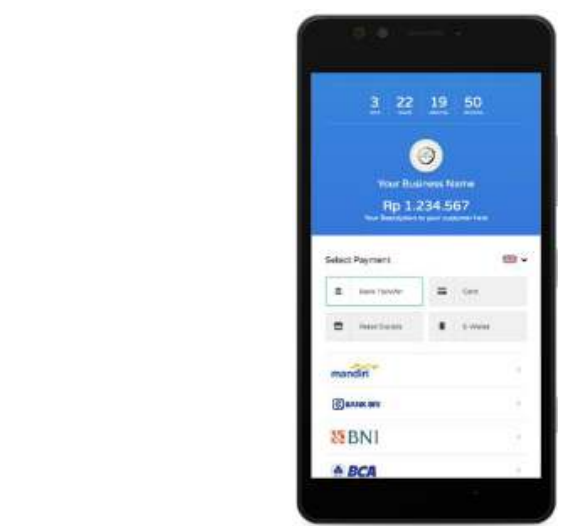

Gambar. 4. User Interface Xendit Invoice

\section{SISTEM PARKIR EZPARKING}

Pada poin ketiga ini akan dijelaskan tentang desain arsitektur dari sistem dan desain interface dari aplikasi untuk penelitian ini. Desain arsitektur akan menjelaskan tentang arsitektur pada penelitian. Desain interface akan menjelaskan tampilan-tampilan dan fitur dari aplikasi pada sistem. Dimana penjelasan desain arsitektur dan desain interface akan dibagi menjadi subbab-subbab yang terpisah.

\section{A. Desain Arsitektur}

Dapat dilihat pada gambar 5 terdapat 5 aktor pada penelitian ini, kelima aktor tersebut adalah admin, owner, supervisor, pegawai, dan member. Kelima aktor ini memiliki peranan penting pada sistem yang akan dibuat. Pertama admin sekaligus pembuat sistem menggunakan komputer untuk melihat statistic yang berupa grafik agar dapat memantau jalannya sistem. Kedua adalah owner, owner mempunyai tugas untuk mendaftarkan tempat parkir pada admin untuk dimasukkan ke dalam sistem. Setelah terdaftar owner dapat membuka halaman admin pada aplikasi mobile dimana halaman ini ditujukan untuk owner, supervisor, dan pegawai. Owner dapat melakukan banyak 
hal pada halaman admin yaitu, membuat newsfeed baru, melihat report, melihat statistic tempat parkir, menambah pegawai atau supervisor.

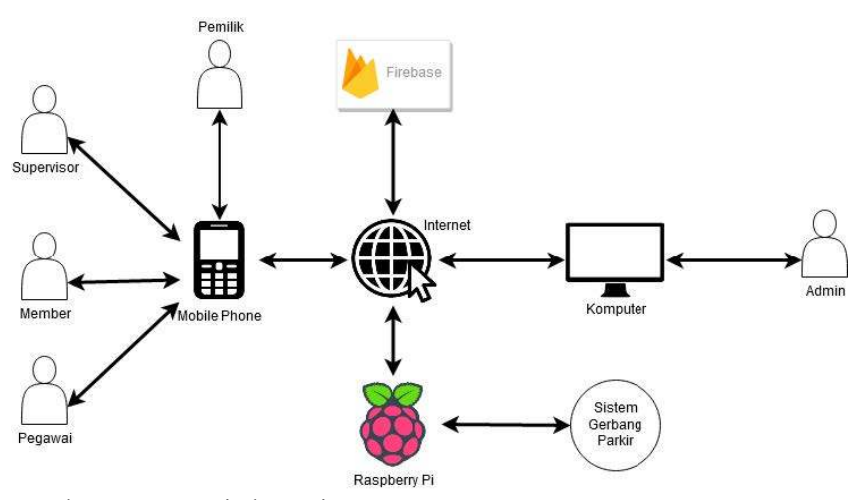

Gambar. 5. Arsitektur Sistem

Supervisor dan pegawai memiliki pekerjaan yang hampir mirip, yang membedakan mereka adalah pada saat melakukan review report, report yang direview oleh pegawai akan disampaikan ke supervisor akan tetapi report yang bukan dari pegawai dan direview langsung oleh supervisor tidak perlu diperiksa oleh siapa-siapa lagi karena supervisor dapat langsung melakukan review akhir. Terakhir adalah member, seluruh owner, supervisor, dan pegawai merupakan member tetapi mereka mempunyai role tambahan tersebut. Member adalah pemakai aplikasi dan sistem tempat parkir dimana member dapat melakukan banyak hal antara lain, melakukan masuk dan keluar parkir, melakukan submit report, melakukan booking, melakukan subscribe, dan melakukan top-up. Itu merupakan seluruh pekerjaan yang dilakukan oleh aktor yang ada pada sistem penelitian ini.

Terdapat 2 fitur penting pada sistem ini, yaitu fitur masuk dan keluar parkir dan melakukan report user. Berikut penjelasan dari masing-masing fitur:

- Masuk dan Keluar Parkir

Proses yang dilakukan oleh fungsi ini adalah melakukan scan QRCode dimana akan dilakukan pembukaan gerbang dan pengambilan gambar sebagai bukti user sudah masuk kedalam parkiran. Setelah masuk, user melakukan parker di area yang telah disediakan. Semua informasi parkir akan tersimpan dalam aplikasi. Pada saat user ingin keluar, user pergi ke gerbang keluar dimana akan menemui QRCode lagi dan user melakukan scan pada QRCode tersebut. Aplikasi akan menunjukan halaman pembayaran untuk user, jika user sudah membayar maka gerbang akan terbuka tetapi jika belum maka user harus menyelesaikan pembayaran agar dapat keluar dari tempat parkir.

- Report User

Pada proses ini merupakan pengiriman report yang dilakukan oleh user untuk melaporkan kendaraan yang melakukan pelanggaran. Report dilakukan untuk memperingati user yang melanggar. User yang ingin mengirimkan report harus mengisi nomor plat dan melakukan foto pada kendaraan yang melakukan pelanggaran tersebut. Setelah itu, user harus mensubmit report. Report kemudian diterima oleh tim dari tempat parkir, dimana tim ini terdiri dari owner, supervisor, dan pegawai. Tim akan melakukan pengecekan ke tempat dan mengisi form jika user bersalah atau bisa juga menilai bahwa kendaraan tidak bersalah sehingga ditekan tombol tidak bersalah. Form yang diisi adalah keterangan kesalahan dan melihat foto yang diambil pada saat masuk gerbang untuk memilih user mana yang melakukan kesalahan. Jika user yang direport terlalu banyak melakukan kesalahan maka user tersebut akan di block dan tidak diijinkan parkir lagi kedepannya.

\section{B. Desain Interface}

Pada subbab ini akan dijelaskan beberapa tampilan yang terdapat dalam sistem, terdapat tampilan pada website dan tampilan pada aplikasi mobile. Gambar 6 merupakan gambar halaman home untuk member pada aplikasi mobile.

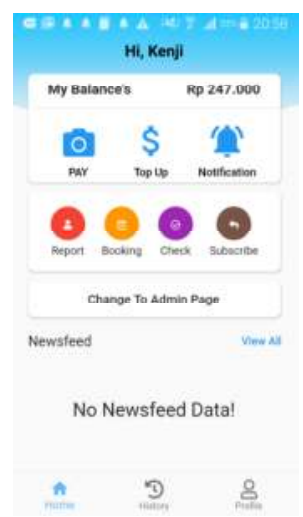

Gambar. 6. Halaman Home

Pada gambar 6 dapat dilihat bahwa terdapat 7 button yang dapat ditekan untuk melakukan fungsi yang diinginkan. Pertama yaitu pay, tombol ini digunakan untuk melakukan scan pada saat masuk dan keluar. Scan dilakukan untuk masuk dan scan keluar untuk melakukan pembayaran agar dapat keluar dari tempat parkir. Kedua yaitu top up, tombol ini akan digunakan sebagai media untuk melakukan pengisian saldo pada akun milik user, pengisian akan dibantu dengan menggunakan payment gateway. Ketiga adalah notification, notification digunakan untuk menyimpan history notification yang pernah diterima oleh user. Keempat adalah report, fitur ini digunakan untuk melaporkan user yang melanggar pada saat parkir. User akan melakukan foto kendaraan dan dikirimkan untuk dilakukan review oleh owner, supervisor, dan pegawai. Kelima adalah booking, user dapat melakukan booking dengan membayar biaya booking dimana slot tempat parkir akan dikosongkan 1 untuk user tersebut. Keenam adalah check, check dapat melihat berapa banyak slot tersisa untuk tempat parkir yang ingin dituju. Terakhir adalah subscribe, fitur ini digunakan untuk melakukan subscribe pada tempat parkir agar saat keluar parkir pada tempat parkir tersebut tidak perlu melakukan pembayaran.

Selanjutnya akan dijelaskan proses melakukan report pada aplikasi. Report dilakukan untuk melaporkan mobil yang melanggar yang kemudian direview oleh petugas dari tempat parkir. Pertama user harus masuk kedalam parkiran untuk dapat melakukan report, kemudian sesudah masuk 
user membuka aplikasi dan mengisi form untuk report. Pada form report terdapat tempat pengisian untuk mengisi plat nomor mobil yang melanggar, setelah mengisi plat nomor mobil maka user diminta untuk melakukan foto pada keadaan mobil tersebut. Setelah selesai melakukan foto maka user baru dapat melakukan submit. Jika submit sudah selesai maka data report akan masuk kedalam database dimana anggota tempat parkir dapat melihat report tersebut melalui review report. Gambar 7 merupakan gambar form report.

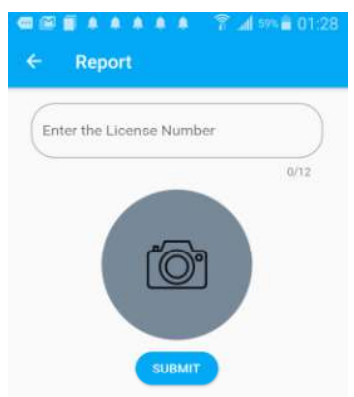

Gambar. 7. Halaman Report

Setelah melihat gambar halaman report pada user maka berikut gambar 8 adalah gambar review report pada tim anggota tempat parkir.
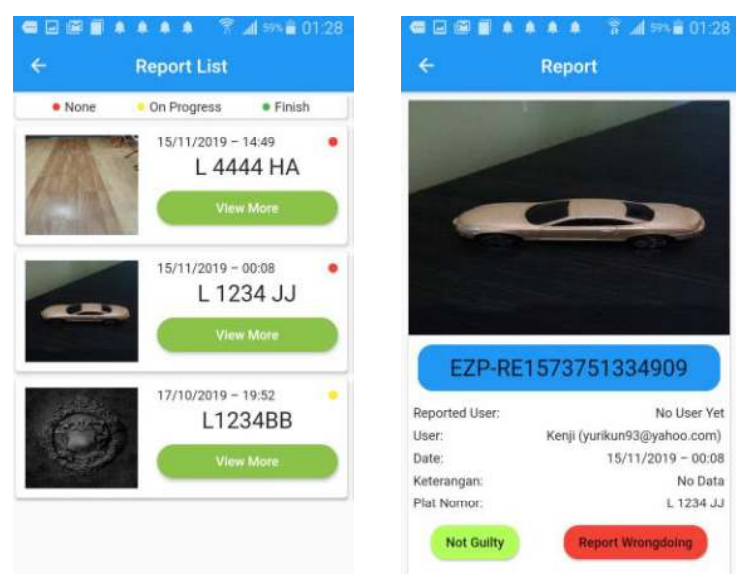

Gambar. 8. Halaman Review Report

Selanjutnya akan ditunjukan desain interface dari halaman admin, dimana halaman ini dikembangkan menggunakan platform website. Melalui halaman ini, admin dapat melakukan berbagai jenis tindakan terkait sistem tempat parkir. Gambar halaman dapat dilihat pada gambar 9.

Pada gambar 9 merupakan tabel transaksi pada halaman admin. Tabel ini digunakan agar admin dapat melihat informasi lebih jelas dan mudah untuk dilihat. Penggunaan tabel sangat berguna karena dapat tersusun dengan rapi.
Selain tabel transaksi ada juga tabel user dan tabel tempat parkir dimana tabel tersebut sama seperti tabel transaksi yang memperlihatkan data dengan bentuk tabel agar mudah untuk dilihat pada layar. Berikutnya akan dijelaskan gambar pada halaman create user, dimana gambar 10 merupakan gambar halaman create user.

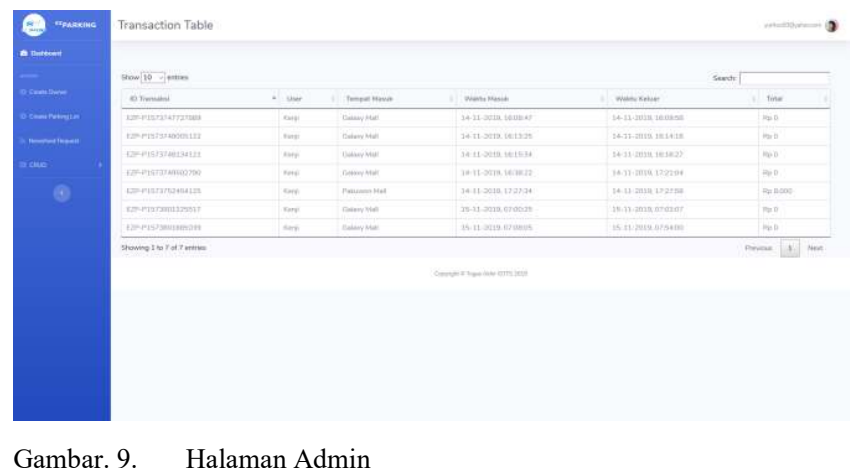

Dapat dilihat pada gambar 10, pembuatan owner dilakukan dengan cara mengisi form yang sudah diberikan oleh admin. Pengisian form akan dilakukan oleh calon owner dan pada waktu pengisian admin akan membantu user jika ada kesulitan yang dialami. Admin juga akan mengarahkan user untuk mempercepat proses pendaftaran. Ada beberapa hal yang harus diisi oleh user yaitu, nama, email, password, pengulangan password, alamat, nomor telpon, jenis kelamin dan persetujuan terms \& conditions. Setelah user mengisi seluruh hal tersebut maka dapat dilanjutkan dengan menekan tombol register account. Penekanan tombol akan melakukan pengecekan jika format email salah, password terlalu lemah, dan checkbox belum dicentang. Pada saat pengecekan selesai dan seluruh hal sudah terpenuhi maka akun user akan terbuat dan user akan ditujukan ke halaman create parking lot.

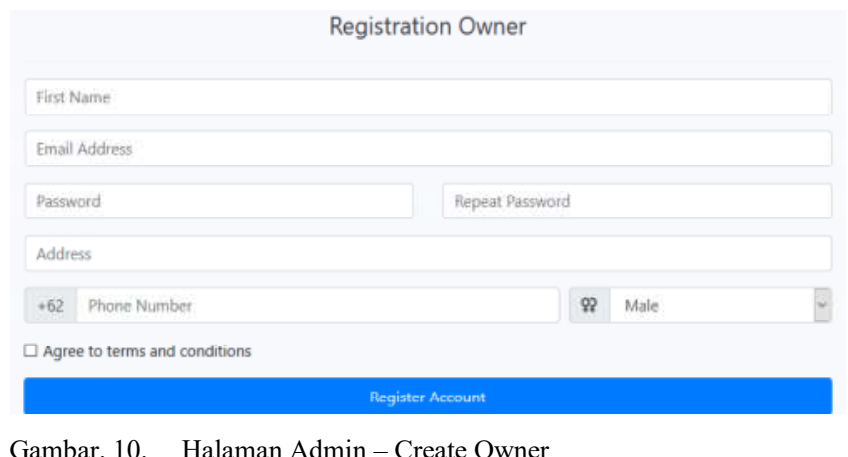

Gambar. 10. Halaman Admin - Create Owner

\section{HASIL EKSPERIMEN DAN PENELITIAN}

Pada bab ini akan diberikan hasil uji coba dari penelitian ini. Uji coba pertama pada sistem dilakukan dengan menggunakan kuisioner (acceptance test) yang memuat pertanyaan seputar penggunaan aplikasi. Uji coba dialkukan oleh 30 responden dimana 1 admin, 20 member, 3 owner, 3 supervisor, dan 3 employee. Berikut ini merupakan tabel yang memuat daftar pertanyaan pada kuesioner beserta persentase jawaban yang diterima dari responden atas kuesioner yang diberikan. 
TABEL I

HASIL UJI COBA KUESIONER

\begin{tabular}{|c|c|c|c|c|c|}
\hline Pertanyaan & 1 & 2 & 3 & 4 & 5 \\
\hline $\begin{array}{l}\text { Bagaimana } \\
\text { Tampilan Aplikasi } \\
\text { Menurut Anda? (19 } \\
\text { User) }\end{array}$ & $0 \%$ & $0 \%$ & $15 \%$ & $68.4 \%$ & $15.8 \%$ \\
\hline $\begin{array}{l}\text { Bagaimana Fitur } \\
\text { yang Ditawarkan } \\
\text { Aplikasi? (19 User) }\end{array}$ & $0 \%$ & $0 \%$ & $10.5 \%$ & $52.6 \%$ & $36.9 \%$ \\
\hline $\begin{array}{l}\text { Apakah Sistem } \\
\text { Parkir Memuaskan? } \\
\text { (19 User) }\end{array}$ & $0 \%$ & $5.2 \%$ & $15.8 \%$ & $31.6 \%$ & $47.4 \%$ \\
\hline $\begin{array}{l}\text { Apakah Fitur Masuk } \\
\text { dan Keluar Parkir } \\
\text { Berjalan dengan } \\
\text { Baik? (10 Member) }\end{array}$ & $0 \%$ & $0 \%$ & $60 \%$ & $20 \%$ & $20 \%$ \\
\hline $\begin{array}{l}\text { Apakah Fitur } \\
\text { Submit Report } \\
\text { Berjalan dengan } \\
\text { Baik? (10 Member) }\end{array}$ & $0 \%$ & $10 \%$ & $10 \%$ & $40 \%$ & $40 \%$ \\
\hline $\begin{array}{l}\text { Apakah Fitur } \\
\text { Subscribe Berjalan } \\
\text { dengan Baik? (10 } \\
\text { Member) }\end{array}$ & $0 \%$ & $10 \%$ & $0 \%$ & $20 \%$ & $70 \%$ \\
\hline $\begin{array}{l}\text { Apakah dengan } \\
\text { Aplikasi ini } \\
\text { Memudahkan untuk } \\
\text { Melakukan Parkir? } \\
\text { (10 Member) }\end{array}$ & $0 \%$ & $0 \%$ & $0 \%$ & $40 \%$ & $60 \%$ \\
\hline $\begin{array}{l}\text { Apakah Fitur } \\
\text { Review Report } \\
\text { Berjalan dengan } \\
\text { Baik? (3 Owner, } 3 \\
\text { Supervisor, } 3 \\
\text { Employee) }\end{array}$ & $0 \%$ & $11.1 \%$ & $22.2 \%$ & $44.5 \%$ & $22.2 \%$ \\
\hline $\begin{array}{l}\text { Apakah Fitur } \\
\text { Submit Newsfeed } \\
\text { Berjalan dengan } \\
\text { Baik? (3 Admin) }\end{array}$ & $0 \%$ & $0 \%$ & $0 \%$ & $66.7 \%$ & $33.3 \%$ \\
\hline $\begin{array}{l}\text { Apakah Fitur Setting } \\
\text { Tempat Parkir } \\
\text { Berjalan dengan } \\
\text { Baik? (3 Admin) }\end{array}$ & $0 \%$ & $0 \%$ & $0 \%$ & $66.7 \%$ & $33.3 \%$ \\
\hline $\begin{array}{l}\text { Apakah dengan } \\
\text { Menggunakan } \\
\text { Aplikasi ini } \\
\text { Memudahkan anda } \\
\text { Melihat } \\
\text { Perkembangan } \\
\text { Tempat Parkir? (3 } \\
\text { Admin) }\end{array}$ & $0 \%$ & $0 \%$ & $0 \%$ & $33.3 \%$ & $66.7 \%$ \\
\hline
\end{tabular}

Berdasarkan tabel 1, pertanyaan yang diberikan mempunyai nilai jawab 1 sampai dengan 5 dimana 1 menunjukan bahwa aplikasi tidak berfungsi dengan baik, dinilai buruk, atau fitur tidak berjalan dengan semestinya sedangkan 5 menunjukan bahwa aplikasi berfungsi sangat baik atau fitur berjalan dengan sesuai.

Sedangkan ujicoba kedua pada sistem ini dilakukan dengan teknik stress test dimana 20 member diminta untuk masuk dan keluar dalam kurun waktu yang hampir bersamaan. Untuk masing-masing jenis palang yang dikembangkan akan diukur waktu proses masuk/keluar rata2 user dan lama waktu tunggu untuk user terakhir yang masuk atau keluar dari tempat parkir. Table 2 merupakan daftar jenis palang beserta perhitungan waktunya.
TABEL II

HASIl Uji COBA WAKTU (DALAM SECOND)

\begin{tabular}{|c|c|c|c|}
\hline Jenis Palang & $\begin{array}{c}\text { Rata-Rata } \\
\text { Proses } \\
\text { Waktu } \\
\text { Masuk }\end{array}$ & $\begin{array}{c}\text { Rata-Rata } \\
\text { Proses } \\
\text { Waktu } \\
\text { Keluar }\end{array}$ & $\begin{array}{c}\text { Waktu } \\
\text { Tunggu } \\
\text { User } \\
\text { Terakhir }\end{array}$ \\
\hline Palang Biasa (Sistem lama) & 12 & 98 & 1247 \\
\hline $\begin{array}{l}\text { Palang Rashberry Phi v1.0 } \\
\text { (Menggunakan scan qrcode } \\
\text { akan tetapi belum memiliki } \\
\text { kemampuan pengelanan } \\
\text { plat nomor dan deteksi } \\
\text { keberadaan mobil) }\end{array}$ & 8 & 8 & 314 \\
\hline $\begin{array}{l}\text { Palang Rashberry Phi v2.0 } \\
\text { (Menggunakan scan qrcode } \\
\text { dan telah memiliki deteksi } \\
\text { keberandaaan mobil) }\end{array}$ & 12 & 12 & 538 \\
\hline $\begin{array}{l}\text { Palang Rashberry Phi v3.0 } \\
\text { (Menggunakan scan qrcode } \\
\text { dan telah memiliki deteksi } \\
\text { keberadaan mobil serta } \\
\text { pengenalan plat nomor) }\end{array}$ & 17 & 12 & 537 \\
\hline
\end{tabular}

\section{KESIMPULAN}

Berikut adalah beberapa kesimpulan yang diperoleh pada penelitian ini, antara lain:

- Penggunaan sistem raspberry pi pada palang parkir dinilai dapat meningkatkan performa dari palang parkir. Mengingat apabila menggunakan raspberry pi sebagai controller dapat digabung dengan berbagai fungsi lain seperti melakukan pengenalan plat nomor, atau mendeteksi keberadaan mobil sehingga palang tidak langsung menutup ketika mobil masih di bawah palang.

- Penggunaan framework flutter dan firebased dalam mengembangkan sistem ini (dalam bentuk aplikasi mobile) memudahkan peneliti dalam mendesain, melayout, dan mengembangkannya. Terutama dalam hal kecepatan dalam pembuatannya.

- $100 \%$ pengguna saat ujicoba menyatakan bahwa sistem ini memudahkan mereka dalam melakukan pemesanan dan pembayaran parkir (dengan rata-rata waktu saat masuk atau keluar tempat parkir adalah dibawah 30 detik). Hal ini menjawab tujuan dari penelitian yaitu menangani permasalahan penumpukan atau antrian parkir.

\section{DAFTAR PUSTAKA}

[1] Flutter Documentation [Online] Available at: https://flutter.dev/docs

[2] Cross-platform mobile app development with flutter [Online] Available at: https://blog.codemagic.io/cross-platform-mobile-appdevelopment-with-flutter/

[3] RaspberryPi Documentation [Online] Available at: https://www.raspberrypi.org/documentation/

[4] Firebase Documentation [Online] Available at: https://firebase.google.com/docs

[5] What is Xendit? [Online] Available at: https://xendit.github.io/xendit$k b /$ Indonesia/about-us/what-is-xendit/

[6] Build beautiful native apps in record time. [Online] Available at: https://flutter.io/.

[7] Belchin, Moises, dan Patricia Juberias. 2015. Web Programming with Dart. New York: Apress.

[8] Caya, Andrew. 2018. The Faster Web with PHP, MySQL, and JavaScript. London: Packt Publishing.

[9] Svennerberg, Gabriel, dan Cameron Turner. 2010. Beginning Google Maps API 3. New York: Apress. 
Kenji Andrean lahir di Surabaya, Jawa Timur, Indonesia pada tahun 1996. Menyelesaikan studi S1 di Program Studi Informatika ISTTS pada tahun 2019.

Hendrawan Armanto lahir di Surabaya, Indonesia, pada tahun 1986. Menyelesaikan studi S1 di program studi Teknik Informatika STTS pada tahun 2008. Menyelesaikan studi masternya pada program studi Teknologi Informasi STTS. Minat penelitian adalah bidang Artificial Intelligent, Evolutionary Algorithm, dan Game Development.

C. Pickerling lahir di Surabaya, Indonesia, pada tahun 1986. Menyelesaikan studi S1 di program studi Teknik Informatika STTS pada tahun 2008. Menyelesaikan studi masternya pada program studi Teknologi Informasi STTS pada tahun 2016. Minat penelitian adalah pada bidang ilmu software engineering dan evolutionary algorithm. 